\title{
NASA Langley Systems Analysis \& Concepts Directorate Technology Assessment/Portfolio Analysis
}

\author{
Stephen Cavanaugh, Trina Chytka, Phil Arcara, Sharon Jones \\ NASA Langley Research Center, Hampton, Virginia 23681 \\ Doug Stanley, Alan Wilhite \\ National Institute of Aerospace, Hampton, VA 23666 \\ Georgia Institute of Technology, Atlanta, GA 30332 \\ $\underline{\text { Introduction }}$
}

\begin{abstract}
Systems analysis develops and documents candidate mission and architectures, associated system concepts, enabling capabilities and investment strategies to achieve NASA's strategic objectives. The technology assessment process connects the mission and architectures to the investment strategies. In order to successfully implement a technology assessment, there is a need to collect, manipulate, analyze, document, and disseminate technology-related information. Information must be collected and organized on the wide variety of potentially applicable technologies, including: previous research results, key technical parameters and characteristics, technology readiness levels, relationships to other technologies, costs, and potential barriers and risks. This information must be manipulated to facilitate planning and documentation. An assessment is included of the programmatic and technical risks associated with each technology task as well as potential risk mitigation plans. Risks are assessed and tracked in terms of likelihood of the risk occurring and consequences of the risk if it does occur. The risk assessments take into account cost, schedule, and technical risk dimensions. Assessment data must be simplified for presentation to decision makers. The Systems Analysis and Concepts Directorate (SACD) at NASA Langley Research Center has a wealth of experience in performing Technology Assessment and Portfolio Analysis as this has been a business line since 1978 .
\end{abstract}

\section{Systems and Technology Engineering}

In order to design a system to meet an operational need, assumptions must be made about the state of the technology base applicable to all components of the system. In order to select and develop technologies in a cost-effective manner, assumptions must be made about the level of benefit that the technology will have to the system or systems in which it would be inserted and employed. Any complete systems engineering framework must include an integrated methodology that addresses engineering and management issues related to the concurrent selection, development and insertion of advanced technologies.

Technology engineering is a distinct discipline, separate from, but highly related to, systems engineering. Technology engineering and systems engineering are usually performed by different organizations, often with different cultures, including employees and managers with different personalities and educational backgrounds. Figure 1 depicts Technology Synergy Teams (TSTs) comprised of technologists and subsystems analysis and Systems Synergy Teams (SSTs) made up of systems engineers and analysis. Technology engineering begins with bottoms-up innovation, often unrelated to any particular system or product, and ends with technology insertion prior to system development. Systems engineering begins with a product focus and does not end until the product is fielded. In technology engineering, requirements are treated more as goals, with a given technology project having a high degree of uncertainty of success at achieving the desired performance on schedule; hence, multiple alternative technology projects are typically managed in parallel within a larger technology program, in order to have fall-back positions to reduce risk. Roadmaps are typically constructed with decision gates to reduce alternatives as progress is made or to introduce new or modified technology projects as required. In systems engineering, the focus is on designing and developing a product to meet the requirements on schedule and cost. 


\section{Technology and System Synergy Teams Nase}

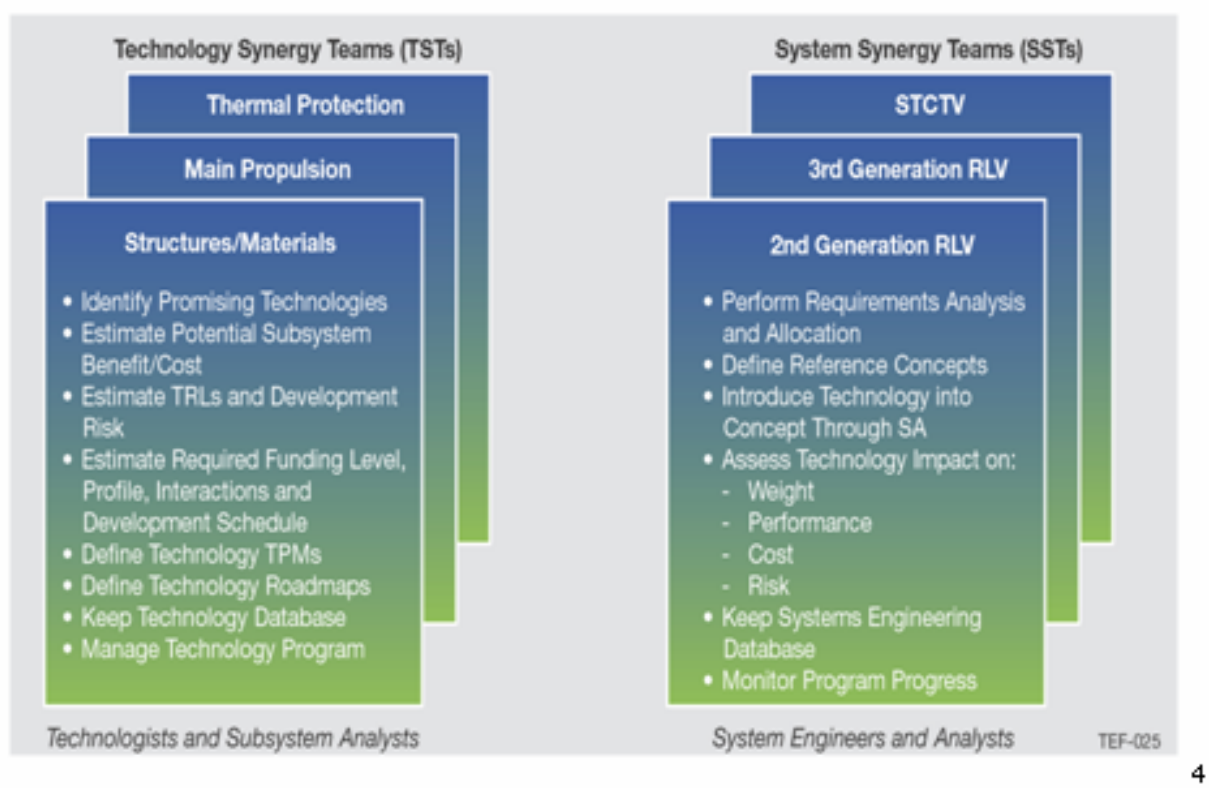

Figure 1 - Technology and System Synergy Teams

The engineering of systems and the technology required to make them successful must often be performed concurrently, with a very high degree of interaction and communication. Any framework for technology engineering must draw on existing systems engineering processes, tools, and methods; take into account the differences between systems engineering and technology engineering; and account for the high degree of interaction required between the concurrent technology and system development programs.

\section{Systems and Technology Engineering Framework}

A technology engineering framework has been developed for the selection, development, and insertion of technologies concurrent with the systems engineering of the system(s) in which the technology will eventually be employed. Figure 2 provides an iterative waterfall flow of the key steps in this technology engineering framework, which include: (1) technology requirements development and analysis, (2) technology prioritization and initial selection, (3) technology program planning, (4) technology program monitoring and management, (5) and technology integration and insertion.

Mission Need and System Requirements: As indicated on the top side of Figure 2, the product-focused process begins with a mission need. This mission need is translated into a system need and associated requirements and eventually into a technology need and associated requirements. This top-down system requirements analysis and allocation process follows standard systems engineering practices; including functional analysis and allocation, systems analysis and trade studies, system design integration, etc. ${ }^{2,3}$

Technology Requirements Development and Analysis: The first major element of the technology engineering framework in Figure 2 is "Technology Requirements Development and Analysis". This is an iterative process consisting of bottoms-up and top-down components. Technology requirements come from a top-down system requirements analysis and allocation approach. System- and subsystem-level requirements are translated into technology requirements through the use of Technology Sensitivity Derivatives (TSDs) and Technology Technical Performance Measures (TTPMs). A TSD is the partial derivative of the change in a system-level requirement (e.g. life-cycle cost, reliability) to a change in TTPM 
(e.g. thermal conductivity, combustion efficiency). A TTPM is a subsystem- or component-level parameter that is readily measurable during the implementation of a given technology project by a knowledgeable technologist.
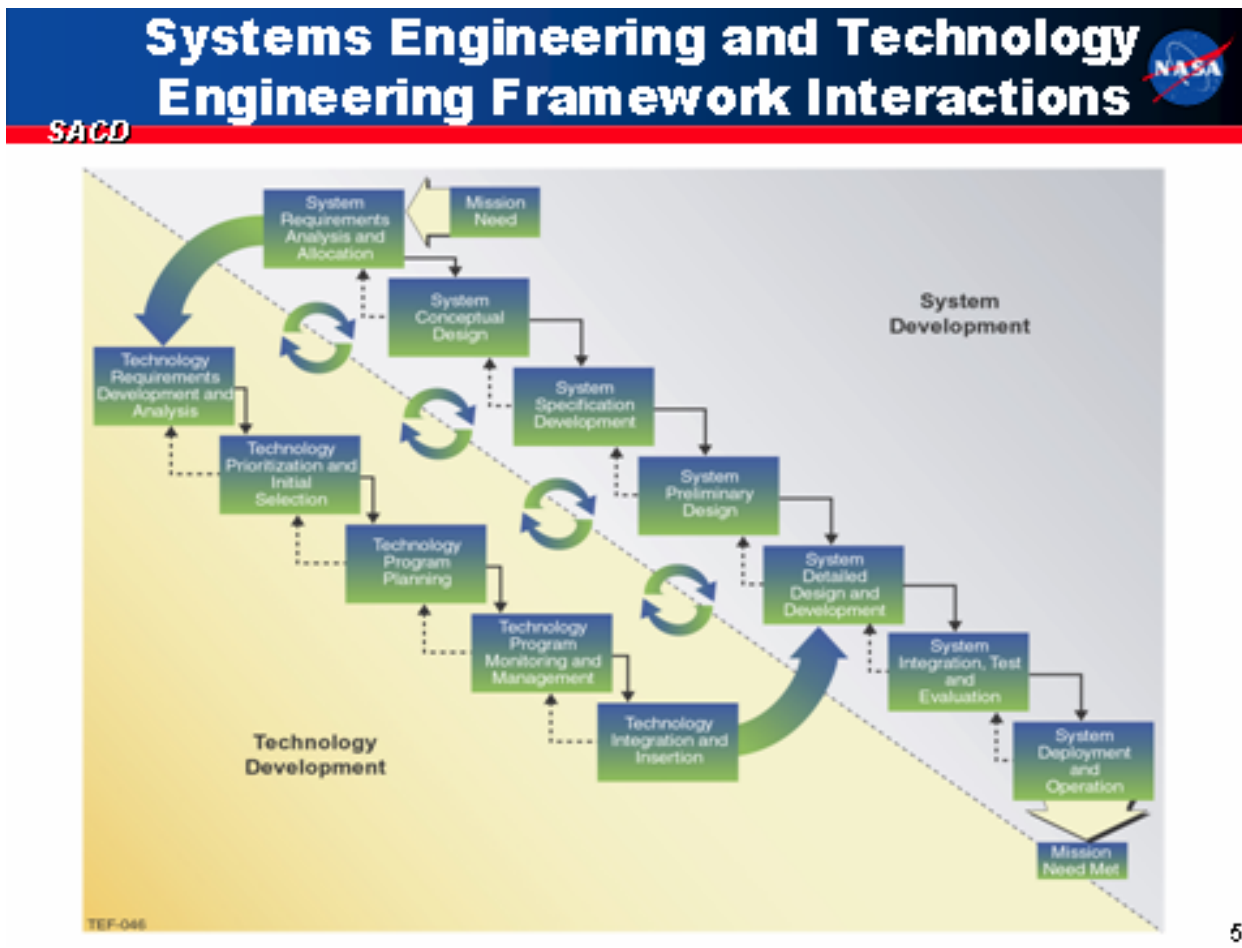

Figure 2 - Systems Engineering and Technology Engineering Framework

The initial set of top-down technology requirements generated through this process are then validated or iterated through a bottoms-up technology identification process involving expert technologists. As shown in the bottom portion of figure 3, promising technologies that have the potential of meeting the identified requirements are identified from the stream of on-going technology basic research. In some cases technologies may be identified that have the potential to exceed the identified requirements, and in other cases, it may not be possible to identify a portfolio of technologies that can meet the requirements in the given timeframe. The technologist can determine which technologies have the highest potential for improvement, and the systems analyst or engineer can determine which technologies have the largest potential impact on the system. Hence, an iterative, collaborative process between technologists and systems analysts and engineers must be executed to identify from the broad pool of promising technologies a smaller set of screened technologies that have the potential to meet or exceed the iterated technology requirements.

For this set of screened technologies, a wide variety of documentation should be developed, including: previous research status and results, key technical details, related TTPMs, current and required Technology Readiness Levels (TRLs), cost and schedule (including milestones) to achieve the required TRLs, an assessment of the risk of achieving the required TRLs, interrelationships with other technologies, and related TSDs and potential system-level benefits. These details should be documented in a database.

This set of screened technologies and documentation will then be used to accomplish the next major element of the technology engineering framework. It should be noted that this initial screening and documentation of promising technologies could be considered as a high-level initial implementation of the first three elements in figure 2, to be followed by a more detailed iteration (e.g. a spiral model). 


\section{Technology Prioritization Approach NAs}

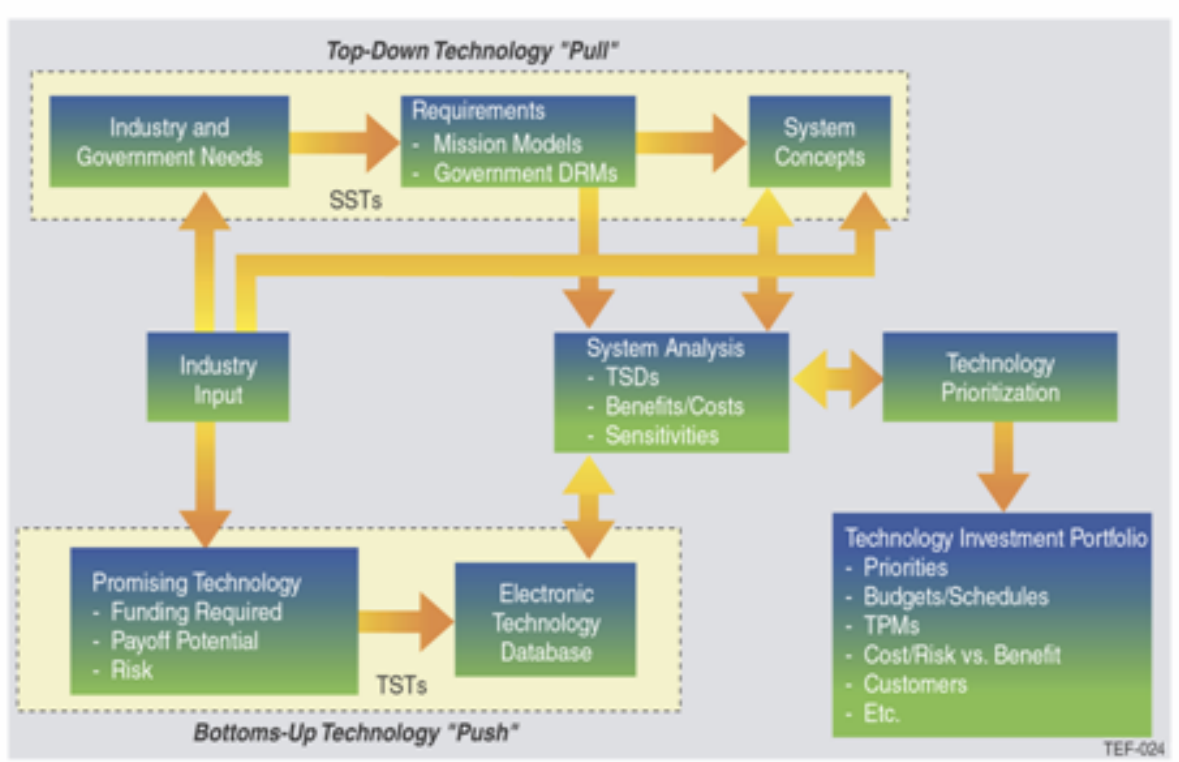

Figure 3 - Technology Prioritization Approach

\section{$\underline{\text { Technology Prioritization and Initial Selection }}$}

The process takes the screened technologies and associated documentation as shown in figure 3 , together with the technology requirements and Technology Sensitivity Derivatives (TSDs), and performs technology prioritization and initial selection to develop a technology investment portfolio for program planning and execution. The prioritization occurs against evaluation criteria derived from the system-level requirements in cooperation with the customer. The prioritization process takes advantage of TSDs, which can be used to quantitatively evaluate the integrated impact of employing a given technology advancement on the system-level Figures of Merit (FOMs).

Although much quantitative data can be made available to assist in the evaluation process, some portion of the evaluation and prioritization process will almost always have to be qualitative in nature because of the large number of technologies and FOMs, the limitations of existing systems analysis models, and the need to often include qualitative evaluation criteria. Any tools and methods used to facilitate this process must take these factors into account.

A large number of processes, tools, and methods have been proposed and demonstrated in recent years for multi-attribute decision making. ${ }^{3,4,5}$ Some of these $\underset{6,7,8}{\operatorname{ap}}$ have been demonstrated to a limited degree for the specific application of technology prioritization. ${ }_{10}^{6,7,8}$ These approaches include the use of the Analytic Hierarchy Process, Quality Function Deployment, ${ }^{10}$ Multi-Attribute Utility Theory ${ }^{11}$-among others. Some of the approaches include methods for dealing with probabilistic risk and uncertainty. ${ }^{5,6,7,8}$ Many of these processes could be adapted and expanded for this application; however, the approach used in this framework should have the following characteristics:

(1) Make maximum use of quantitative data;

(2) Include the capability to perform qualitative and quantitative evaluations;

(3) Allow collaborative, real-time participation by experts and stakeholders; 
(4) Provide a method for weighting evaluation criteria or combining them into a utility function;

(5) Allow the evaluation of costs as well as benefits;

(6) Allow the integrated evaluation of technologies against multiple systems;

(7) Include consideration of incompatibilities or interactions between technologies;

(8) Include the capability to assess uncertainty and quantify risk;

(9) Allow the performance of sensitivity analyses and visualization of results;

(10) Be well-founded in mathematical theory;

(11) Be easy to understand and explain; and

(12) Be systematic, repeatable, objective and open to scrutiny.

It is important in the process of managing complex aerospace programs to understand the technical, schedule, and cost risks of each technology required to achieve the goals of the program. In addition to the internal program assessments of risks, it is prudent to have independent assessments of risk conducted by qualified experts outside of the day-to-day program. Conducted properly, these independent assessments can provide unbiased insight to program management to support technical and programmatic planning and decision-making. The objective of technology development risk assessment is to use all available program information to estimate the risk that each of the technologies under development will not be sufficiently mature to meet system level requirements within the time and fiscal constraints of the program. The assessment addresses both technical and programmatic (schedule and cost) risks. These assessments are conducted independent of any internal program risk management processes that might be in use.
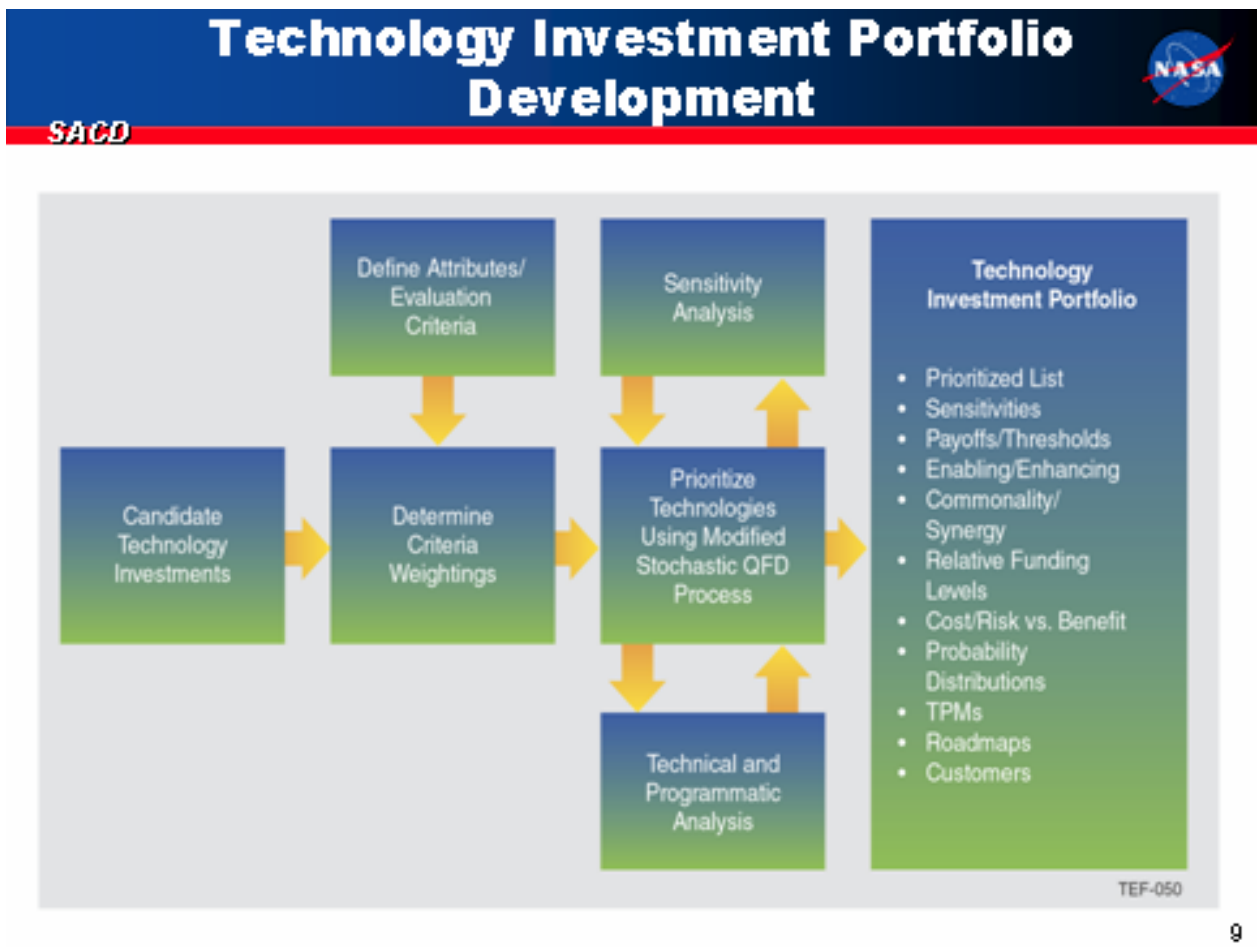

Figure 4 - Technology Investment Portfolio Development

The output of this process is a portfolio of prioritized technologies, see figure 4 , for potential investment and inclusion into an integrated technology development program. This process can be kept in a database format and continually updated as required by changes in requirements and FOMs, system designs, technology program progress, etc. The selected portfolio of technologies is then used to provide a recommended prioritized technology budget profile.

Examples of Langley SACD technology assessment and portfolio analysis experiences are given 
below:

\section{High-Speed Research (HSR) Program (1990-1999)}

The HSR technology tracking and assessment process was the process by which NASA and its industry partners measured the technical progress of the program's technology development efforts. Metrics were established for each technology area and tracked against end-of-program projections. The process was probabilistic in nature and consisted of two phases. The technology audit phase was where the data was gathered and compared to previous assessments. The metrics integration phase was where uncertainties in system-level FOMs of merit are quantified by using a Monte-Carlo approach to propagate uncertainties at the technology level.

The objective of the NASA HSR program was to develop the technologies (see figure 5) necessary to design, develop, manufacture, field, and support a High Speed Civil Transport that was both economically viable and environmentally acceptable. Phase I of the HSR Program successfully identified technologies that mitigate environmental concerns. The focus in Phase II was on technologies in the areas of aerodynamics, propulsion, structures and materials, and flight deck systems that address issues of economic viability.

The benefits from research and development expenditures on technology advancement and subsequent synthesis of the resultant technologies into a final application or product are not always obvious. During the program's conceptual phase, when many promising technologies were being identified and explored, the end-results of a specific technology development effort were difficult to forecast. Technology breakthroughs and failures will occur. The nature and frequency of these occurrences were challenging to predict with any degree of certainty. Therefore, one aspect of technology development program management should be to acknowledge the presence of uncertainty, measure and track it, and, if possible, reduce the uncertainty to an acceptable level ${ }^{11}$.
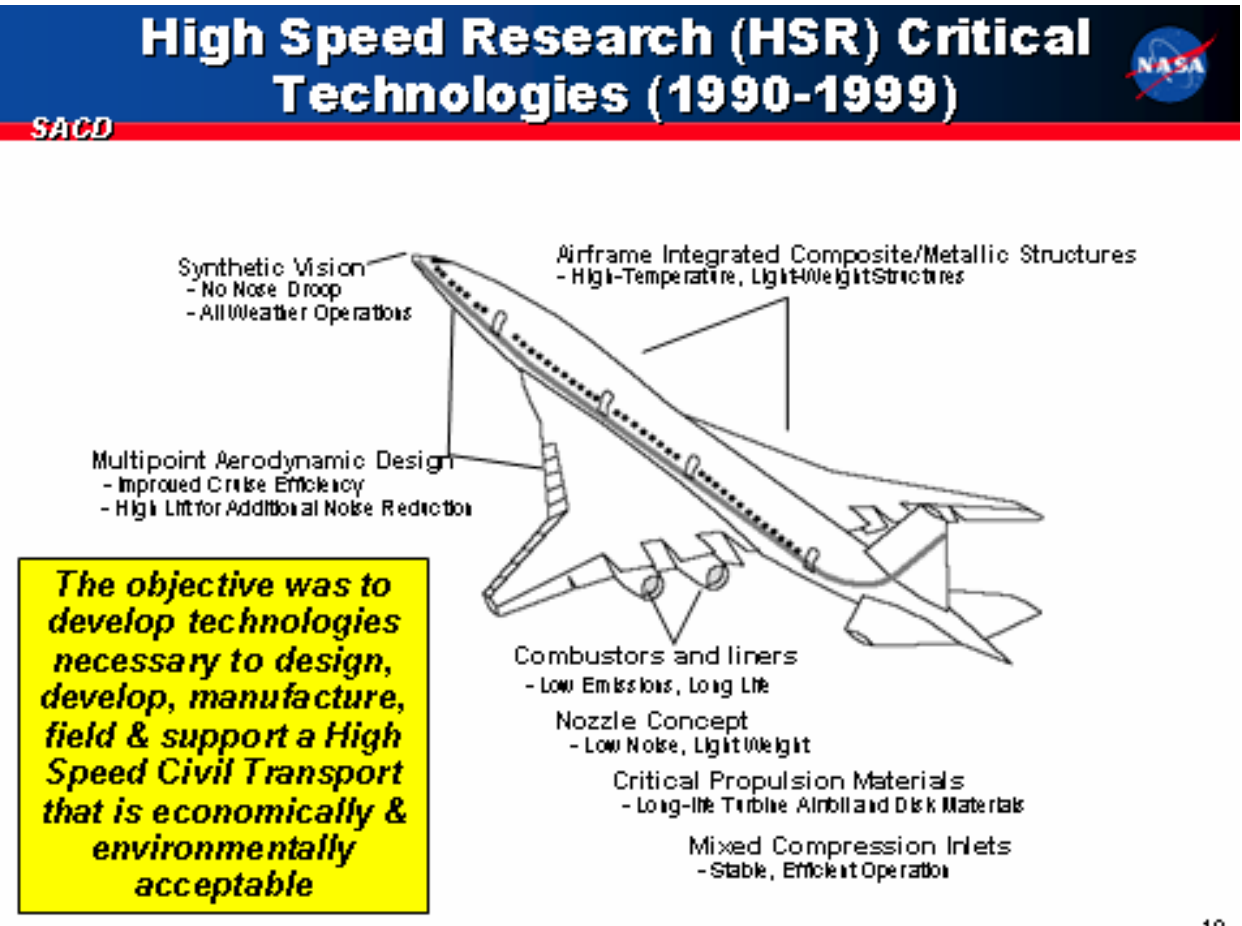

Figure 5 - High Speed Research Critical Technologies 


\section{Evaluating Technology Impacts on Mission Success of Future Launch Vehicles (1999-2002)}

A process was developed for tracking focused technology development by integrating system and uncertainty analyses. Uncertainties were developed for single-stage and two-stage reusable launch concepts from historical weight estimating relationships that are typically used during the concept definition phase of a system. Other uncertainties were developed based on empirical data and NASA guidelines. The uncertainties were integrated into the systems analysis model, and a Monte Carlo simulation was conducted to determine the integrated uncertainty probability. The results (see figure 6) showed there is a 31 percent weight growth (4.3 payloads) uncertainty in dry weight between a 50 percent and 95 percent probability for the Single-Stage-to-Orbit concept. The Bimese concept (two identical Single-Stage concepts mated and sized for two-stage performance) resulted in a reduction in both weight (12 percent) and uncertainty (15 percent or 1.8 payloads). These uncertainties are similar to the NASA guideline for weight growth of spacecraft. Finally, the present process was extended as a model for measuring the progress of technology development programs.

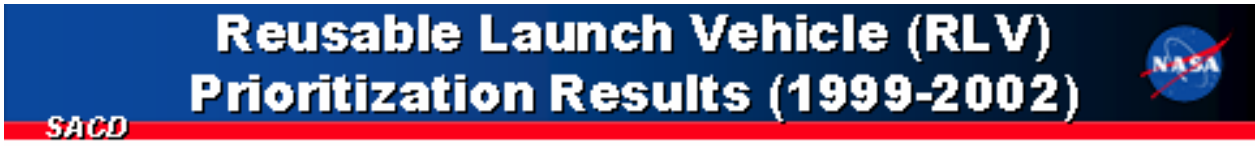

\begin{tabular}{|c|c|c|c|c|c|c|c|c|c|}
\hline Technology/Advanced Development Task & $\begin{array}{l}\text { Human } \\
\text { Safety }\end{array}$ & $\begin{array}{l}\text { System } \\
\text { Reliab }\end{array}$ & $\begin{array}{l}\text { Mission } \\
\text { Perform }\end{array}$ & $\begin{array}{c}\text { Develop } \\
\text { Cost }\end{array}$ & $\begin{array}{l}\text { Prod } \\
\text { Cost }\end{array}$ & $\begin{array}{l}\text { Ops } \\
\text { Cost }\end{array}$ & $\begin{array}{l}\text { Tech } \\
\text { Feas }\end{array}$ & $\begin{array}{l}\text { Dual } \\
\text { Use }\end{array}$ & Total \\
\hline (Woightings) & $30 \%$ & $20 \%$ & $10 \%$ & $12.5 \%$ & $5 \%$ & $7.5 \%$ & $7.5 \%$ & $7.5 \%$ & \\
\hline \multicolumn{10}{|l|}{ Top Ten } \\
\hline RS-2100 Prototype Engine Integrated Test-Bed & 5 & 5 & 5 & 5 & 4 & 5 & 1 & 3 & 90.0 \\
\hline Full-Scale Dia. LH2 Tank/insulation/TPS Demo & 4 & 4 & 4 & 5 & 4 & 4 & 1 & 3 & 78.5 \\
\hline Enhanced FFSSC IPD Integrated Test-Bed & 4 & 4 & 4 & 4 & 3 & 4 & 3 & 3 & 76.0 \\
\hline High Pressure Fuel Turbopump & 4 & 4 & 4 & 4 & 3 & 4 & 3 & 3 & 76.0 \\
\hline High Pressure Oxidizer Turbopump & 4 & 4 & 4 & 4 & 3 & 4 & 2 & 3 & 74.5 \\
\hline Jet Boost Pumps & 4 & 4 & 4 & 3 & 3 & 4 & 3 & 3 & 73.5 \\
\hline High-Reliablity Embedded Sensors & 5 & 5 & 2 & 1 & 0 & 3 & 2 & 5 & 71.5 \\
\hline Full-Scale Dia. LO2 Tank/Insulation/TPS Demo & 3 & 3 & 5 & 4 & 3 & 4 & 2 & 3 & 66.5 \\
\hline Integrated Avionics/SWIVHM Ground Demo & 4 & 4 & 3 & 2 & 0 & 4 & 2 & 3 & 64.5 \\
\hline Control and IEHM & 4 & 4 & 2 & 1 & 0 & 4 & 2 & 4 & 61.5 \\
\hline
\end{tabular}

Figure 6 - Reusable Launch Vehicle Prioritization Results

\section{Capability Requirements Analysis and Integration (CRAI) (2003-2005)}

The CRAI team was chartered (see figure 7) to identify and prioritize the capabilities and technologies that must be developed before the Nation's Space Vision can be attained. Reporting to the Space Architect, the CRAI team was organized around nine critical capability areas to accomplish this goal. In keeping with the One NASA philosophy, membership of the CRAI Team was drawn from across the National Aeronautics and Space Administration (NASA). An Independent Technology Assessment Team (ITAT) was also formed to assess the data generated by the CRAI Team, to prioritize capabilities, and to identify capability gaps.

In addition to nuclear propulsion and power capabilities, the following are CRAI examples of critical capabilities for which significant advances beyond the current state-of-the-art (SOA) will be needed to pursue the President's vision. Prioritization of the technologies required to enable these capabilities will be heavily influenced by the specifics of design reference missions and architectures and the launch capability 
AIAA 2006-7029

to LEO.

- High reliability computing systems

- Integrated Systems Health Management (ISHM)

- Thermal protection systems

- In-space propulsion

- Extra-Vehicular Activity (EVA) suits

- Closed-loop life support systems

- In-space storage, transfer, and management of cryogenic fluids

- Surface/sub-surface mobility

- Radiation and Micro-meteorite Orbital Degree (MMOD) protection

- Lightweight thermal management

The CRAI process produced a very large, well documented, and easily referenced database of capabilities and technologies. 13

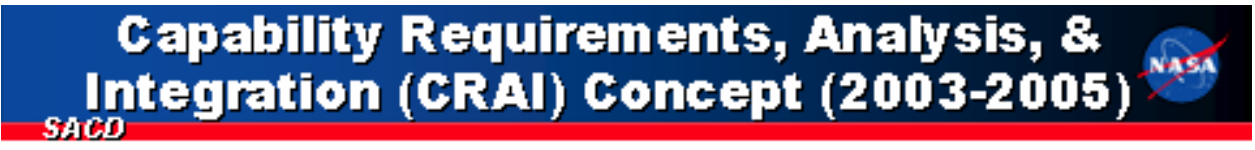

- Identification, assessment, prioritization, and strategic investment recommendations of capabilities needed to realize the NASA mission.

- Integrates capabilities across the Agency Enterprises, looking for connections and leverage opportunities.

- OneNASA analysis approach, products, and teams. Purposefully modeling OneNASA behavior.

- A structured, open, strategic analysis process with traceability to NASA missions and objectives
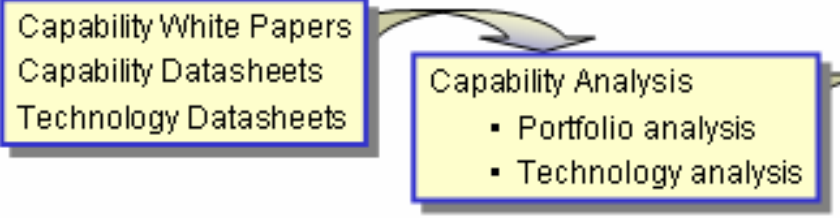

Strategic Capability

Investment

Recommendations

Figure 7 - Capability Requirements, Analysis, \& Integration Concept

\section{Vehicle Systems Program (VSP) portfolio analysis (2004-2005)}

An assessment was performed to project the potential benefits of Vehicle Systems Program (VSP) portfolio of advanced technologies on a fleet of subsonic transports. This activity was a joint effort involving analysts from LaRC's Systems Analysis Branch (SAB) and GRC's Aerospace Systems Analysis Office (ASAO), in concert with Georgia Tech's Aerospace Systems Design Laboratory (GT/ASDL). This task was the 2 nd of three planned FY05 analyses agreed to by VSP's Vehicle Integration, Strategy and Technology Assessment (VISTA), the Subsonic Transport (ST) Vehicle Sector Manager and the NASA systems analysis organizations (SAB \& ASAO). 
The approach to performing this analysis (see figure 8) consists of resizing a set of subsonic transport reference vehicles to take advantage of the potential benefits of VSP technologies. The resulting advanced vehicle characteristics are then compared to the reference vehicles in order to measure the potential progress towards the Goals/Objectives/Capabilities of the Subsonic Transport Vehicle Sector. Advanced vehicles were analyzed for a 5-year and a 15-year timeframe ${ }^{14}$.

The Subsonic Transport Sector Analysis Team has completed evaluation of the applicable current VSP technology portfolio against the Subsonic Transport Sector goals and critical 15-year capabilities. The analysis was performed on four separate vehicles including a 70 passenger regional jet, a 150 passenger mid-range transport, a 300 passenger long-range transport, and a 300 passenger long range Blended-WingBody transport. The results indicate that Empty Weight, SFC, Engine T/W and LTO NO long term goals may be achievable. However, little or no progress is being made towards achieving the $\mathrm{L} / \mathrm{D}$ goal. The Noise Reduction community is considering revising the metric used for community noise, which, in turn, would lead to a more realistic target goal value. Results clearly demonstrate the need for a rigorous systems analysis approach since technologies focused on improving one goal often have negative impacts on multiple other goals/capabilities. Also, the interdependencies of different goals can produce counter productive results as indicated by the L/D vs. Empty Weight dilemma. One final point is that for this analysis a current TRL is associated with each technology analyzed, hence one should have more confidence in the potential benefits of the higher TRL technologies.

The VSP Return on Investment (ROI) calculator ${ }^{15}$ was created to allow the Vehicle System Analysts and decision makers to quantitatively visualize the benefit to the commercial aviation industry from the VSP technology roadmaps. Each metric was changed from its normal unit of measure into a monetary benefit through an individualized conversion. To make an accurate assessment of the impact on the commercial aviation system, a fleet growth model and a user-defined advanced vehicle introduction rate were used to model the air transportation system of the future. These components were brought together to quantify the overall return on investment from the VSP portfolio.

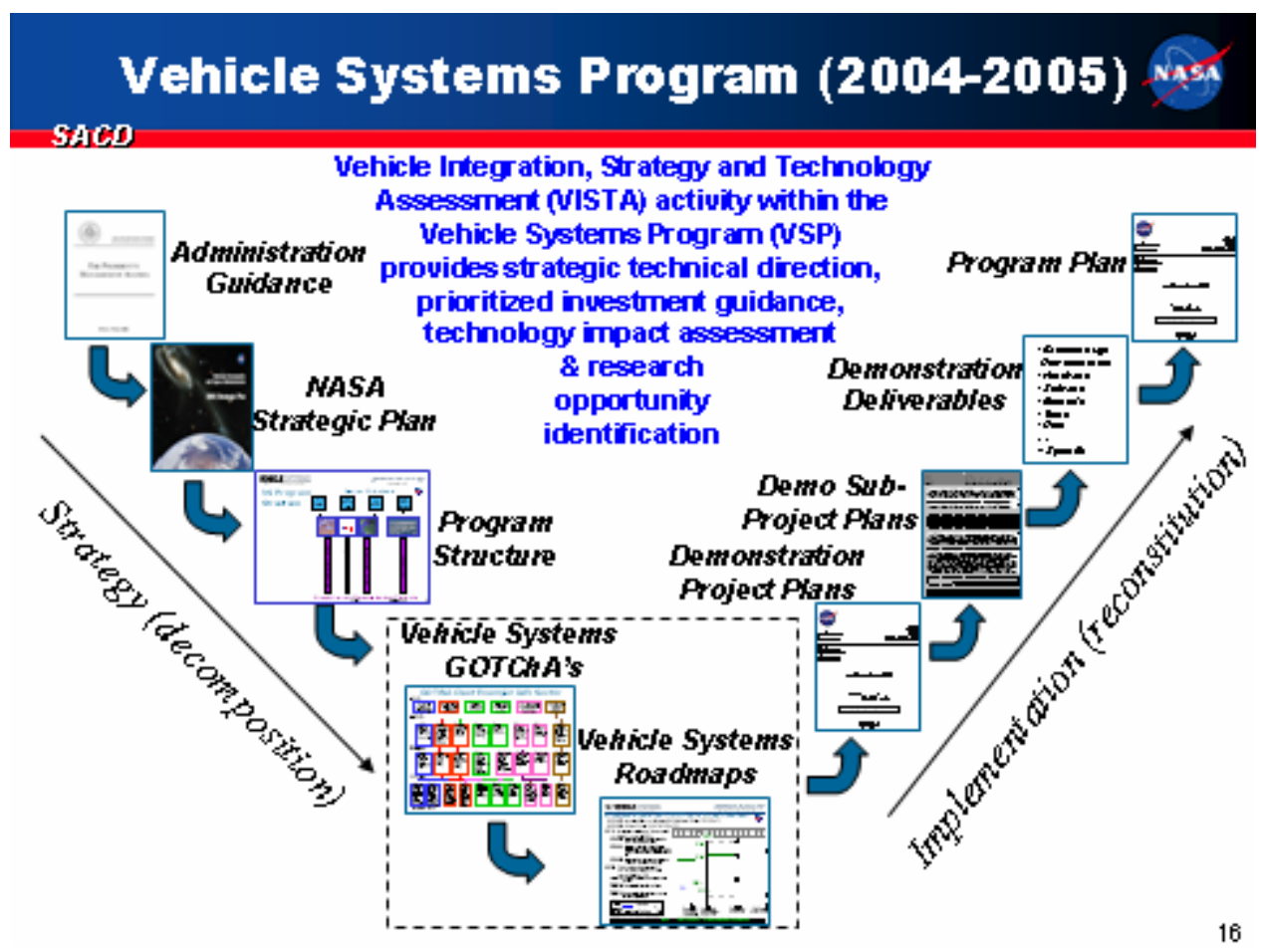

Figure 8 - Vehicle Systems Program 


\section{Exploration Systems Architecture Study (ESAS) (2005)}

In May of 2005, NASA initiated the Exploration Systems Architecture Study (ESAS). The purpose of the study was to:

1) Assess the top-level Crew Exploration Vehicle (CEV) requirements and plans that enable the CEV to provide crew transport to the International Space Station (ISS);

2) Define top-level requirements and configurations for crew and cargo launch systems to support the lunar and Mars exploration programs;

3) Develop a reference exploration architecture concept to support sustained human and robotic lunar exploration operations; and

4) Identify key technologies required to enable and significantly enhance these reference exploration systems and a reprioritization of near-term and far-term technology investments.

SACD had significant roles in supporting the ESAS study team. SACD performed the liaison risk assessment functions between the ESAS team and an agency wide team charged with using the Shuttle to complete the ISS by 2010. SACD performed numerous Lunar Surface Access Module (LSAM) trades to define top level element requirements and establish architecture propellant needs. The technology assessment process (see figure 9) was developed and implemented by SACD as the ESAS architecture was refined.
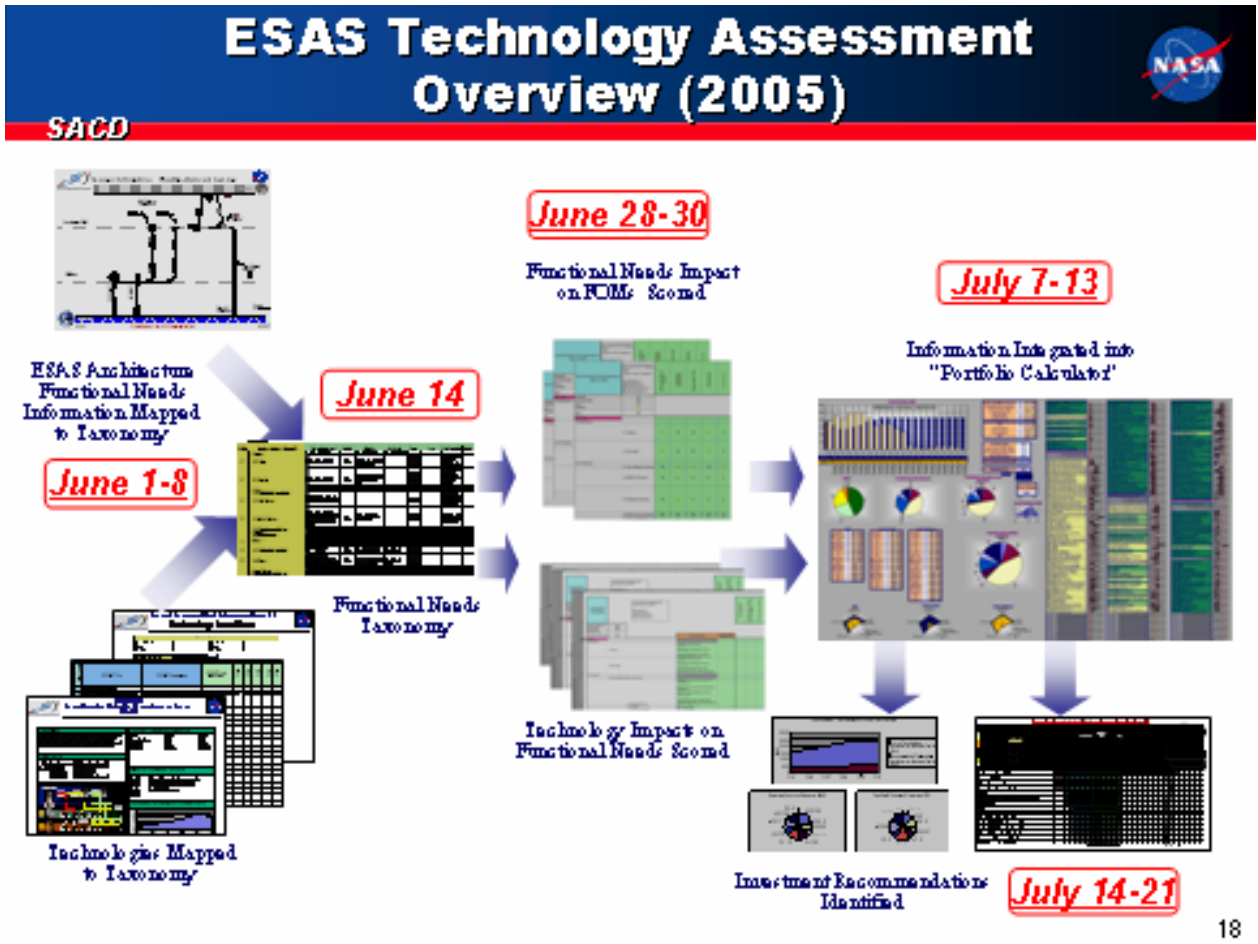

Figure 9 - ESAS Technology Assessment Overview

\section{Summary}

This paper has developed and presented a technology engineering framework for the selection, development, and insertion of technologies concurrent with the systems engineering of the system(s) in which the technology will eventually be employed. The technology engineering framework developed and presented in this paper draws on existing systems engineering processes, tools, and methods; takes into account the differences between systems engineering and technology engineering; and accounts for the high degree of interaction required between the concurrent technology and system development programs. 
The major steps in the technology engineering process are: (1) technology requirements development and analysis, (2) technology prioritization and initial selection, (3) technology program planning, (4) technology program monitoring and management, (5) and technology integration and insertion. Process, tools and personnel exist with SACD to perform technology assessment and portfolio analysis studies for the Agency either in direct support to a program and/or in an honest broker fashion.

\section{References}

${ }^{1}$ NASA Systems Engineering Handbook - SP-610S, June 1995.

2 Stanley, Douglas. “Technology Engineering: The Concurrent Development of Space Transportation Systems and Technology”. Paper presented at the AIAA Space Conference in 2003.

3 Blanchard, Benjamin S. and Wolter J. Fabrycky. Systems Engineering and Analysis. Upper Saddle River, New Jersey: Prentice-Hall Inc., 1998.

Sage, Andrew P.. Systems Engineering. New York, New York: John Wiley \& Sons, Inc., 1992.

${ }^{5}$ Bandte, Oliver. "A Probabilistic Multi-Criteria Decision Making Technique for Conceptual and Preliminary Aerospace Systems Design." Ph.D. diss., Georgia Institute of Technology, 2000.

${ }^{6}$ Curran, Frank, Eric Christensen, Daric Escher, Pat Odom, Sammy McNully, Neal Lovell, and Bill Pannell. "Propulsion Technology Assessments Within NASA's Integrated Technology Assessment Center." Paper presented at the 37th AIAA/ASME/SAE/ASEE Joint Propulsion Conference, Salt Lake City, UT: July 2001.

${ }^{7}$ Kirby, Michelle R. and Dimitri N. Mavris. "A Method for Technology Selection Based on Benefit, Available Schedule and Budget Resources." Paper presented at the 2000 World Aviation Conference, San Diego, CA: October 2000.

${ }^{8}$ Mavris, Dimitri N. and Michelle R. Kirby. "Technology Identification, Evaluation, and Selection for Commercial Transport Aircraft." Paper presented at the 58th Annual Conference of the Society of Allied Weight Engineers, San Jose, CA: May 1999.

9 Saaty, T. L. The Analytic Hierarchy Process: Planning, Priority Setting, and Resource Allocation. New York, New York: McGraw Hill, 1980.

10 Akao, Y.. Quality Function Deployment. Cambridge, MA: Productivity Press, 1990.

11 Ward, Clay, A. "Technology Tracking for the High-Speed Research Program”. Paper presented at the 1998 World Aviation AIAA Conference, September 1998.

12

Wilhite, Alan; Gholtson, Sampson E.; Farrington, Phillip A.; Swain, James J. "Evaluating Technology Impacts on Mission Success of Future Launch Vehicles.” Paper presented at the 52 International Astronautical Congress, October, 2005.

${ }^{13}$ Lord, Robert; Cavanaugh, Stephen; Craig, Douglas. "Independent Assessment of the Capabilities and Technologies Identified by the Capability Requirements Analysis and Integration (CRAI) Team”. Final report dated December 16, 2004. 
Arcara, Phil; Haller, Bill. "Bottoms Up Benefit Assessment of Currently-Funded (FY04) Vehicle Systems Program's Technology Portfolio as Applied to the Subsonic Transport Sector”. Paper dated April 8, 2005.

15

Mavris, Dimitri N. and Michelle R. Kirby. “Quantitative VSP Return on Investment Calculator”. Paper dated January 30, 2006.

16

${ }^{16}$ Wilhite, Alan; Odom, Pat; Lovell, Neal; Lord, Robert; Stanley, Douglas. "Estimating the Risk of Technology Development.” Paper presented at the ASME Conference on November, 2003.

17

Jones, Sharon Monica; Reveley, Mary. "An Overview of the NASA Aviation Safety Program Assessment Process.” 